\title{
EDITORIAL
}

\section{Drivers of racial disparities in prostate cancer trial enrollment}

(C) The Author(s), under exclusive licence to Springer Nature Limited 2021

Prostate Cancer and Prostatic Diseases (2021) 24:946-947; https:// doi.org/10.1038/s41391-021-00427-z

Despite clinical trials providing evidence for the best practice in managing cancer patients, only $2-7 \%$ of cancer patients in the United States (US) enroll in clinical trials [1]. Of patients with prostate cancer enrolled on registrational trials, Lythgoe et al. inform us that only $2.9 \%$ are self-reported Black or African American race, and most other racial minorities were enrolled at $\leq 0.5 \%$ [2]. The authors eloquently highlight an issue that has existed for years, the underrepresentation of multiple racial minorities in clinical trials. Undoubtedly, this issue is complex and multifactorial, but what are some known causes for this disparity?

\section{ACCESSIBILITY}

Galsky et al. evaluated metastatic prostate cancer clinical trials and found that $50.2 \%$ of trials would require a one-way drive of $>60$ min for patients to access clinical trial sites [3]. Furthermore, in a study conducted to identify barriers to clinical trial enrollment, Lara et al. found that travel distance was one of the most common reasons for refusing enrollment [4].

\section{FINANCIAL TOXICITY}

As trials becoming increasingly complex, it is common for frequent study visits that are billed as follow-up visits and not covered by the study. In addition, extra "standard-of-care" lab tests are ordered for trial participants, which may not be ordered if not on the clinical trial and the financial burden is left on the patient.

\section{MISTRUST}

We need only to point to the centuries of oppression, marginalization, and experimentation on Black and minority communities at the hands of the medical community and society-at-large to understand why. This history has led Black and minority patients to have higher levels of perceived discrimination and deception [5]. Mistrust ultimately results in discordance of treatment recommendations and lack of trial participation [6]. We must acknowledge and address mistrust.

\section{CATCHMENT}

A clinical trial with $3 \%$ of patients being of Black or African American race may appear like a disparity, but we must not forget the concept of catchment. It is important to acknowledge that some of the trials highlighted by Lythgoe et al. are multinational clinical trials that collaborate with countries with small populations of racial minorities. It is expected for very few racial minorities to be enrolled even if there were access and no history of mistrust. However, none of the listed clinical trials reported estimates of each center's catchment racial distribution, and thus it is hard to estimate the extent of the disparity. Trials that are enrolled predominately in the United States may exacerbate this disparity. As we previously reported, $\sim 12 \%$ of men in the United States are Black or African American, prostate cancer is $\sim 1.5$ fold more common in Black men, then prostate cancer trials should have closer or in excess of $18 \%$ of patients enrolled being of the Black race [7]. In this case, an enrollment of $10 \%$, nearly triple what was reported by Lythgoe et al., may still represent a substantial disparity.

One of the only clinical trial groups that have successfully managed to consistently enroll Black or African American men on prostate cancer trials ( $15 \%$ of patients on average are Black) is RTOG/NRG Oncology. Thus, overcoming the racial disparity in trial enrollment has successfully been achieved. It now needs to be replicated by others, including drug companies that run the majority of registrational trials. This starts with more attention being paid to the catchment areas of centers that operate clinical trials. This is closely linked to accessibility. Many institutions may not include sufficient minority communities in their catchment area for various reasons. Understanding the demographic makeup of institutional catchment areas can allow trial groups to be more intentional when selecting clinical trial sites and also participate in targeted outreach and engagement to repair the damage and mistrust. A better understanding of the communities included in our trials combined with community outreach will profoundly impact trial participation and address many of the disparities that arise from a lack of representation. The vicious cycle of poverty, decreased trial enrollment, reduced access to care, and worse outcomes will continue unless we make intentional changes to our clinical trial infrastructure and improve community outreach and engagement.

Randy Vince Jr $\mathbb{D}^{1 凶}$ and Daniel E. Spratt $\mathbb{D}^{2}$
${ }^{1}$ Department of Urology, University of Michigan, Ann Arbor, MI, USA.
${ }^{2}$ Department of Radiation Oncology, University Hospitals, Case
Western Reserve University, Cleveland, OH, USA.
${ }^{\bowtie}$ email: virandy@med.umich.edu

\section{REFERENCES}

1. Murthy VH, Krumholz HM, Gross CP. Participation in cancer clinical trials: race-, sex-, and age-based disparities. JAMA. 2004;291:2720-6.

2. Lythgoe MP, Krell J, Savage P, Prasad V. Race reporting and diversity in US Food and Drug Administration (FDA) registration trials for prostate cancer; 2006-2020. Prostate Cancer Prostatic Dis. (2021). https://doi.org/10.1038/s441391-021-00361-0.

3. Galsky MD, Stensland KD, McBride RB, Latif A, Moshier E, Oh WK, et al. Geographic accessibility to clinical trials for advanced cancer in the United States. JAMA Intern Med. 2015;175:293-5.

4. Lara PNJr Jr, Higdon R, Lim N, Kwan K, Tanaka M, Lau DH, et al. Prospective evaluation of cancer clinical trial accrual patterns: identifying potential barriers to enrollment. J Clin Oncol. 2001:19:1728-33.

5. Smirnoff M, Wilets I, Ragin DF, Adams R, Holohan J, Rhodes R, et al. A paradigm for understanding trust and mistrust in medical research: the Community VOICES study. AJOB Empir Bioeth. 2018;9:39-47. 
6. Dean LT, Moss SL, McCarthy AM, Armstrong K. Healthcare system distrust, physician trust, and patient discordance with adjuvant breast cancer treatment recommendations. Cancer Epidemiol Biomark Prev. 2017;26:1745-52.

7. Spratt DE, Osborne JR. Disparities in castration-resistant prostate cancer trials. J Clin Oncol. 2015;33:1101-3.

\section{COMPETING INTERESTS}

DES: Personal Fees-Janssen, Boston Scientific, AstraZeneca, Blue Earth. Funding-Janssen.

\section{ADDITIONAL INFORMATION}

Correspondence and requests for materials should be addressed to R.V.Jr.

Reprints and permission information is available at http://www.nature.com/ reprints

Publisher's note Springer Nature remains neutral with regard to jurisdictional claims in published maps and institutional affiliations. 